\title{
Heat loss from the upper extremities and clothing thermal comfort
}

\begin{abstract}
This mini-review aimed to examine

a. The effects of different skin areas between extremities and torso covered by clothing on changes of body core temperature during exercise.

b. To what extent hand vasodilation contributes to heat losses from the extremities and clothing thermal comfort during exercise.

In experiment 1 , seven subjects performed bicycle ergometer exercise at a $\mathrm{T}_{\mathrm{a}}$ of $30^{\circ} \mathrm{C}$. Subjects wore two different types of clothing: A, designed to expose upper extremities and $\mathrm{B}$, designed to expose the torso, covered identically $74 \%$ skin of body surface area. At the end of $60-\mathrm{min}$ exercise, $\mathrm{T}_{\mathrm{re}}$ increased to $37.88^{\circ} \mathrm{C}$ in clothing $\mathrm{A}$ and to $38.14^{\circ} \mathrm{C}$ in clothing B, respectively. The results clearly showed that the upper extremities are more efficient than the torso for heat dissipation from the body. In experiment 2, seven subjects performed 25-min exercise and 20-min recovery period after exercise at a $\mathrm{T}$ of $20.0^{\circ} \mathrm{C}$. In OCCL, both wrists were occluded to stop the hand blood flow with a cuff for $30 \mathrm{~min}$ from the 15 th min of exercise to the end of the experiment. In CONT, the wrists were not occluded throughout the experiment. In CONT, finger $\mathrm{T}_{\text {sk }}$ increased from $20.5^{\circ} \mathrm{C}$ to $34.0^{\circ} \mathrm{C}$, and forearm $\mathrm{T}_{\text {sk }}$ increased concomitantly from $25.4^{\circ} \mathrm{C}$ to $27.7^{\circ} \mathrm{C}$ during and after exercise. In OCCL, however, $\mathrm{T}_{\text {sks }}$ in the finger and forearm did not increase at all during wrist occlusion. Despite of a compensatory increase in thermo-physiological responses, $\mathrm{T}$, was significantly higher in OCCL than in CONT. We have confirmed that hand vasodilation (mainly through AVAs) plays an important role for enhancing heat dissipation through the venous blood returning from the hands, consequently suppressing increase of body temperature and enhancing clothing thermal comfort during heat load.
\end{abstract}

Keywords: hand vasodilation, arteriovenous anastomoses, clothing thermal comfort, extremities, torso
Volume 3 Issue 2 - 2017

\section{Kozo Hirata}

Faculty of Home Economics, Kobe Women's University, Japan

Correspondence: Kozo Hirata, Faculty of Home Economics, Kobe Women's University, 2-I, Aoyama, Higashi-suma, Suma, Kobe, 654-8585, Japan, Tel 8I787372094, Fax 8I787372094, Email k-hirata@suma.kobe-wu.ac.jp

Received: August 30, 2017| Published: October 27, 2017
Abbreviations: AVAs, arteriovenous anastomoses; HR, heart rate; $\mathrm{RH}$, relative humidity; $\mathrm{T}$, ambient temperature; $\mathrm{T}_{\mathrm{re}}$, rectal temperature; $\mathrm{T}_{\mathrm{sk}}$, skin temperature; $\mathrm{T}_{\mathrm{es}}$, esophageal temperature; CONT, control experiment; OCCL, occlusion experiment; $\mathrm{M}_{\mathrm{sw}}$, local sweating rate; LDF, skin blood flow; MAP, mean arterial pressure; TPR, total peripheral resistance; SC, traditional soccer uniform; IC, islamic athletic clothing

\section{Introduction}

The increasing core temperature is reduced work capacity due to elevated heat strain. ${ }^{1,2}$ To avoid thermoregulatory problems due to impaired heat dissipation, therefore, clothing with low thermal resistance or clothing covered with little of the surface area of the body is needed in the warm environment or during exercise. Davis et $\mathrm{al}^{3}$ have investigated comparing women's Islamic athletic clothing (IC) and traditional soccer uniform (SC) in a hot environment. They have showed that thermal sensation, sweating sensation, skin wetness, clothing humidity and clothing comfort were significantly greater with IC compared to SC during exercise. Clothing comfort has been defined which is affected by multiple factors including skin temperature and moisture ${ }^{4}$ It is important to consider the clothing comfort from basic points of view, as the extremities vs. the torso skin.

It has been reported that arms act as an important avenues for vascular heat dissipation from the central circulation. ${ }^{5}$ Acral region of the extremities, particularly, have an advantage over the rest of the extremities for heat loss.

The surface of the hands represents only $5 \%$ of the body surface area. However, the surface to mass ratio is 10 times greater in the hand than in the trunk. Moreover, there are many arteriovenous anastomoses (AVAs) in the fingers, ${ }^{6}$ which have a greater blood vessel diameter. Comparing an AVA of $100 \mu \mathrm{m}$ diameter with a capillary of $10 \mu \mathrm{m}$ diameter, the blood flow rate per unit length will be 10,000 times greater in the AVA than in the capillary. ${ }^{7,8}$ It has been recently reviewed that the relationship between AVAs in the human skin and their role in temperature control. ${ }^{9}$

We have demonstrated that heat loss from the forearm is largely accelerated by the returning venous blood flow through the hand AVAs during heat load. ${ }^{10,11}$ If this heat loss mechanism is more effective, it may be considered that the increased hand blood flow greatly contributes to dissipate heat through the extremities from the central circulation without a less additional vasodilation in the other skin area during thermal load.

The present study was to examine

i. The effects of different skin areas between extremities and torso covered by clothing on changes of body core temperature during exercise. 
ii. Whether hand blood flow contributes to thermoregulatory responses and clothing thermal comfort during heat load induced by exercise.

\section{Extremities vs torso}

To investigate the effects of different skin areas between extremities and torso covered by clothing on changes of body core temperature during exercise, 7 healthy female volunteers were participated. Their physical characteristics were as follows: aged 22.0 year (means), height $159.1 \mathrm{~cm}$ and weighing $51.9 \mathrm{~kg}$. Procedures were carefully explained and all subjects gave their informed consent. Subjects performed bicycle ergometer exercise at the heart rate (HR) level of $120 \mathrm{bpm}$ for $30-\mathrm{min}$ and then at the HR level of $150 \mathrm{bpm}$ for $30 \mathrm{~min}$, in the climatic chamber at an ambient temperature $\left(\mathrm{T}_{\mathrm{a}}\right)$ of $30^{\circ} \mathrm{C}$ and relative humidity $(\mathrm{RH})$ of $60 \%$.

Subjects wore two different types of clothing covered identically $74 \%$ skin of body surface area (Figure 1): clothing A, designed to expose upper extremities, while covering the rest of the body, and clothing $\mathrm{B}$, designed to expose the torso covering the rest of the body.

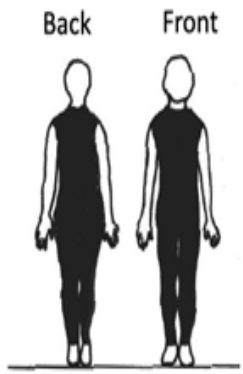

A

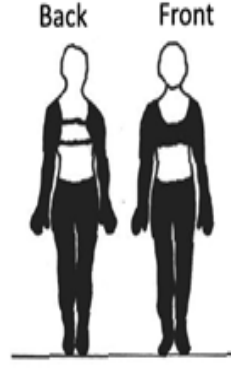

B

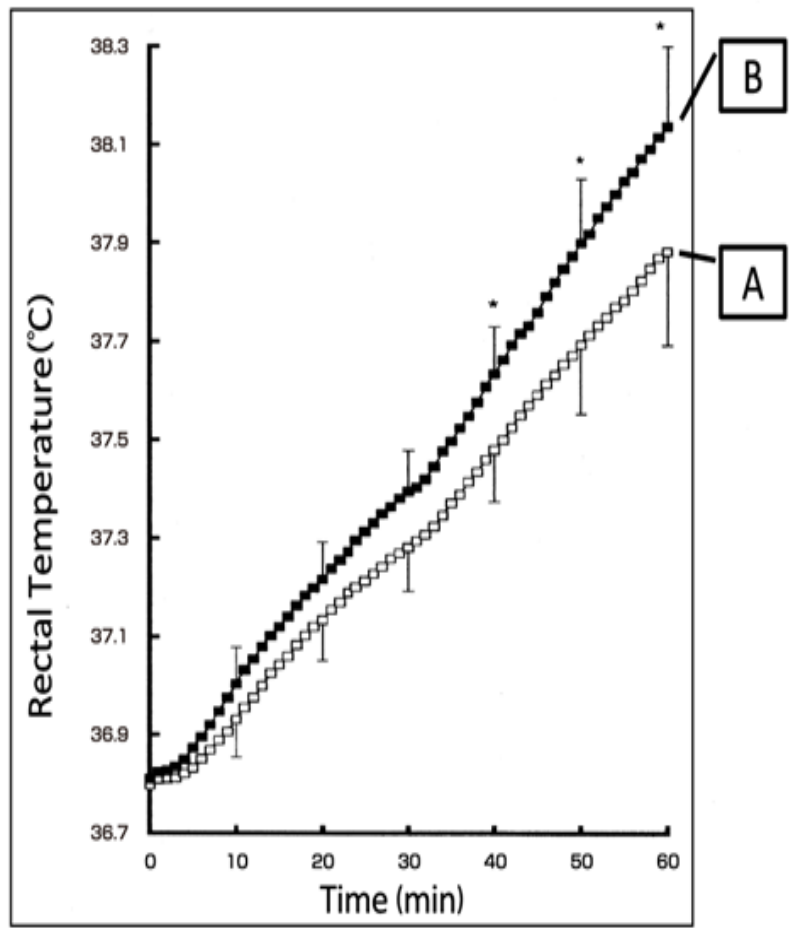

Figure I Changes in rectal temperature during bicycle exercise for $60 \mathrm{~min}$ when subjects wore clothing $A$ and $B$. Himeno ${ }^{12}$ with permission.
Figure 1 showed changes in rectal temperature $\left(T_{r e}\right)$ measured with a thermistor probe inserted $10 \mathrm{~cm}$ beyond the anal sphincter, with clothing A or B during bicycle exercise for 60-min. Mean level of $\mathrm{T}_{\mathrm{re}}$ at the end of exercise was $37.88^{\circ} \mathrm{C}$ in clothing $\mathrm{A}$ and $38.14^{\circ} \mathrm{C}$ in clothing $\mathrm{B}$, respectively. ${ }^{12}$ There was a significant difference in $\mathrm{T}_{\mathrm{re}}$ of $0.26^{\circ} \mathrm{C}$ between both clothing A and $\mathrm{B}$.

These results clearly showed that clothing a designed to expose upper extremities, is more efficient for heat dissipation from the hands and arms than clothing $\mathrm{B}$ designed to expose the torso during exercise under warm condition. Why upper extremities are so effective to promote heat dissipation from the human body?

\section{Contribution of hand vasodilation (mainly blood flow through AVAs)}

The present study was examined whether hand vasodilation contributes to thermo-physiological responses during exercise. This study involved 7 healthy male volunteers, aged 30.6year (means), height $168.9 \mathrm{~cm}$ and weighing $63.8 \mathrm{~kg}$. Procedures were carefully explained and all subjects gave their informed consent. The study consisted of occlusion experiments (OCCL) and control experiments (CONT), which include 30-min rest, 25-min bicycle exercise at the HR of 120-130bpm and 20-min recovery period after exercise, in the climatic chamber at a $\mathrm{T}_{\mathrm{a}}$ of $20.0^{\circ} \mathrm{C}$ and $\mathrm{RH}$ of $30 \%$. In OCCL, both wrists were occluded to stop the hand blood flow with a cuff inflated at a pressure of $250 \mathrm{mmHg}$ for $30 \mathrm{~min}$ from the 15 th min of exercise to the end of the experiment. In CONT, the wrists were not occluded throughout the experiment.

In CONT, finger skin temperature $\left(\mathrm{T}_{\mathrm{sk}}\right)$ increased from $20.5^{\circ} \mathrm{C}$ to $34.0^{\circ} \mathrm{C}$, and forearm $\mathrm{T}_{\text {sk }}$ increased concomitantly from $25.4^{\circ} \mathrm{C}$ to $27.7^{\circ} \mathrm{C}$ during and after exercise. In OCCL, however, $\mathrm{T}_{\text {sks }}$ in the finger and forearm did not increase at all during wrist occlusion for $30 \mathrm{~min}$. There were significantly higher skin temperatures of head, trunk, thigh and foot in OCCL than in CONT during and after exercise. Esophageal temperature $\left(\mathrm{T}_{\mathrm{es}}\right)$ measured as body core temperature, increased during exercise and then gradually decreased after exercise in both conditions. $\mathrm{T}_{\text {es }}$ was $0.2^{\circ} \mathrm{C}$ higher in OCCL than in CONT after exercise $\left(\mathrm{P}<0.05\right.$, Figure 2 Bottom panel) ${ }^{13}$

Changes in local sweating rate $\left(\mathrm{M}_{\mathrm{sw}}\right)$ on the chest measured by the ventilation method, and skin blood flow (LDF) on the chest measured by a laser-Doppler flowmeter, are shown in Figure 2 (Top and second panels). Both $\mathrm{M}_{\mathrm{sw}}$ and LDF were significantly facilitated after wrist occlusion $(\mathrm{P}<0.05)$. HR rose to approximately $120-130 \mathrm{bpm}$ during exercise and decreased after exercise in both experiments. These changes were not significantly different between CONT and OCCL.

Mean arterial pressure (MAP) calculated from systolic and diastolic blood pressures which were measured each minute by an electric sphygmomanometer, increased by approximately $20 \mathrm{mmHg}$ at the onset of exercise in both experiments. Wrist occlusion induced a significant fall in MAP during exercise $(\mathrm{P}<0.05$, Figure 2 third panel $)$. MAP was kept at a constant higher level during exercise in CONT. MAP in OCCL was significantly lower than in CONT during the wrist occlusion period $(\mathrm{P}<0.05)$. It appears that decreased MAP with wrist occlusion resulted from decrease of total peripheral resistance (TPR) due to skin vasodilation in the trunk and possibly in the other skin area such as head, thigh and foot, for the compensation of thermoregulatory responses. MAP is mainly the result of two factors: cardiac output and TPR, fundamentally. As HR did not show any change with wrist 
occlusion in the present study, it is indicated that the cardiac output in OCCL do not differ from that in CONT. Therefore, it is suggested that the decreased MAP in OCCL is due to the fall in TPR accompanied with skin vasodilation in wide areas such as head, trunk, thigh and foot, at least.
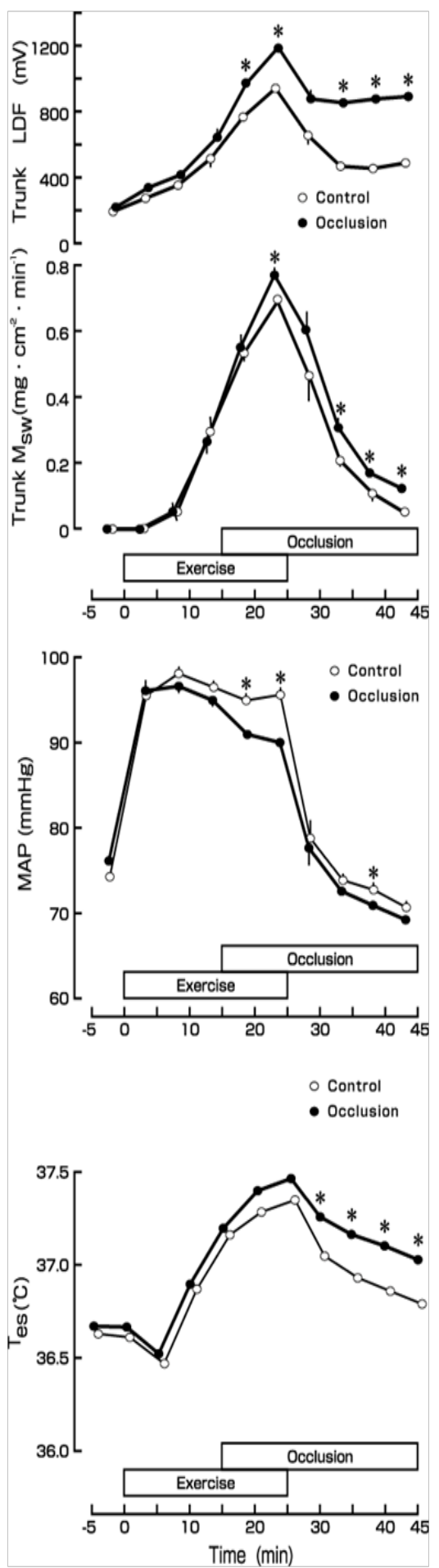

Figure 2 Effects of wrist occlusion from 15th to 45 th min on changes in trunk skin blood flow (LDF), trunk sweating rate $\left(\mathrm{M}_{\mathrm{sw}}\right)$, mean arterial pressure (MAP) and esophageal temperature $\left(T_{e s}\right)$ during thermal load induced by exercise. Nagasaka et al. ${ }^{13}$ Modified by the author with permission.
When the hand vasodilation is stopped as shown in OCCL, the rise of the heat loss from the whole upper limbs is suppressed. Then, the compensatory increases in $\mathrm{M}_{\mathrm{sw}}$ and LDF on the trunk skin (Figure 2 Top and second panels) and increased $\mathrm{T}_{\text {sks }}$ in head, thigh and foot were induced at least, but the additional increase of heat loss from the parts of the body may not be enough to compensate the reduced heat loss from the extremities induced by wrist occlusion. $\mathrm{T}_{\mathrm{es}}$ was, therefore, significantly higher in OCCL than in CONT (Figure 2 Bottom panel).

The present results clearly demonstrated that the hand vasodilation induced the efficacious responses in thermo-regulation and blood pressure regulation during heat load. Compared with CONT, the higher $\mathrm{T}_{\mathrm{es}}$ and the lower MAP were shown in the OCCL during and after exercise. When the hand vasodilation is maintained, the heat losses from not only the hand but also the forearm are increased. The mechanism of the enhancing evaporative and non-evaporative heat losses from the forearm due to hand vasodilation was shown in our previous studies. ${ }^{10,11}$ We have showed that a $1{ }^{\circ} \mathrm{C}$ rise of hand skin temperature caused a $0.3^{\circ} \mathrm{C}$ increase in forearm skin temperature after hand vasodilation. As shown in Figure $3,{ }^{11}$ a great amount of heat was transferred to the forearm by the still warm superficial venous blood returning from the hand.

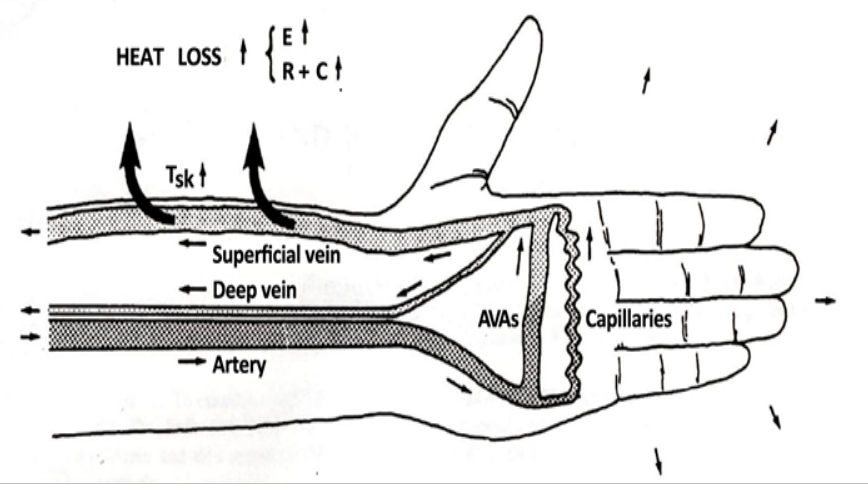

Figure 3 Scheme of enhancing evaporative $(E)$ and non-evaporative $(R+C)$ heat losses from the forearm through the venous blood flowing superficially from the hand. Hirata et al." Applied for the permission.

There are abundant AVAs in the nail-beds of the fingers and in the glabrous skin of the hands. The density is described as being between $600 \mathrm{AVAs} / \mathrm{cm}^{2}$ in nail-beds and $100 \mathrm{AVAs} / \mathrm{cm}^{2}$ in the skin of the thenar and hypothenar regions of the hand. ${ }^{14}$ It has been reported that $78 \%$ of the finger blood flow passes through AVA vessels. ${ }^{15}$ With opening the AVA vessels in the hand, the put-through of heat is considerable, and the returning warm venous blood greatly increases forearm skin temperature (Figure 3). The increased forearm skin temperature as a local factor promotes the rise in forearm sweating rate. The effect of local skin temperature has been described as having a peripheral influence which modifies the output from the central controller in the determination of the local sweat rate. ${ }^{16}$ Bullard et al. ${ }^{17}$ MacIntyre et al. ${ }^{18}$ have also established the importance of the local skin temperature in the determination of local sweating rate and have suggested that its effect is related to the internal temperature drive via some multiplicative mechanisms. According to our previous study, ${ }^{11}$ $60 \mathrm{~W} \cdot \mathrm{m}^{-2}(43 \%)$ out of $140 \mathrm{~W} \cdot \mathrm{m}^{-2}(100 \%)$ of total heat loss including evaporative heat loss from the forearm is originated from the venous blood flow returning from the hand after hand vasodilation (mainly blood flow through AVAs). 


\section{Conclusion}

The present results showed that the increased hand blood flow, with efficacious vasodilation without fall in mean arterial pressure, greatly contributes to enhance evaporative and non-evaporative heat losses from the extremities during thermal load. We have confirmed that hand vasodilation (mainly through AVAs) plays an important role for enhancing heat dissipation through the venous blood returning from the hands, consequently suppressing increase of body temperature and enhancing clothing thermal comfort during heat load. These results suggest that clothing should be considered to expose upper extremities for maintaining clothing thermal comfort and physiological functions in the warm environment.

\section{Acknowledgements}

The author gratefully acknowledges the cooperation of all our subjects.

\section{Conflicts of interest}

There are no conflicts of interest to declare.

\section{References}

1. Goldman RF. Tolerance time for work in the heat when wearing CBR protective clothing. Mil Med. 1963;128:776-786.

2. Speckman K, Allan A, Sawka M, et al. Perspectives in microclimate cooling involving protective clothing in hot environments. Int J Ind Ergon. 1988;3(2):121-147.

3. Davis JK, Bishop PA, Zhang Y, et al. Fluid balance, thermal stress, and post exercise response in women's Islamic athletic clothing. Eur J Appl Physiol. 2012;112(2):725-734.

4. Fanger PO. Thermal comfort. Danish Technical Press, Copenhagen 1970;2(1):12-32.

5. Aulick LH, Robinson S, Tzankoff SP. Arm and leg intravascular temperatures of men during submaximal exercise. J Appl Physiol. 1981;51(5):1092-1097.

6. Sherman JL. Normal arteriovenous anastomoses. Medicine (Baltimore). 1963;42:247-267.
7. Hales JRS. Skin arteriovenous anastomoses, their control and role in thermoregulation. In: Krogsgaard-Larsen P, Christensen SB, editors. Cardiovascular shunts, Alfred Benzon Symposium 21, Munksgaad, Copenhagen, Denmark, 1984. p. 1-16.

8. Molyneux GS, Bryden MM. Comparative aspects of arteriovenous anastomoses. In: Harrison RJ, Holmes RL, editors. Progress in anatomy. USA: Cambridge University Press; 1981. p. 207-227.

9. Walløe L. Arterio-venous anastomoses in the human skin and their role in temperature control. Temperature. 2015;3(1):92-103.

10. Hirata K, Nagasaka T, Noda Y. Venous return from distal regions affects heat loss from the arms and legs during exercise-induced thermal loads. Eur J Appl Physiol. 1989;58(8):865-872.

11. Hirata K, Nagasaka T, Hirashita M, et al. Increase in evaporative and non-evaporative heat loss from the forearm depends on venous return from the hand during exercise. In: Mercer JB, editor. Thermal Physiology. Amsterdam: Elsevier Science; 1989. p. 155-159.

12. Himeno T. The effects of differences between limbs and torso on thermoregulatory responses. Thesis for master degree, Graduate School of Life Sciences, Kobe Women's University, Kobe, Japan; 1997. p. 1-41.

13. Nagasaka T, Hirata K, Hirai A, et al. Significance for physical fitness and sports medicine of cutaneous arteriovenous anastomoses. Descente Sports Science. 1997;18:3-13.

14. Popoff NW. The digital vascular system-With reference to the state Glomus in inflammation Artriosclerotic gangrene, diabetic gangrene thrombo-angiitis obliterans and supernumerary digits in man. Arch Pathol. $1934 ; 18: 295-330$

15. Coffman JD, Cohen AS. Total and capillary finger blood flows in Raynaud's phenomenon. $N$ Engl J Med. 1971;285(5):259-263.

16. Nadel ER, Bullard RW, Stolwijk JAJ. Importance of skin temperature in the regulation of sweating. J Appl Physiol. 1971;31(1):80-87.

17. Bullard RW, Banerjee MR, MacIntyre BA. The role of the skin in negative feedback regulation of eccrine sweating. Int $J$ Biometeorol. 1967;11(1):93-104.

18. MacIntyre BA, Bullard RW, Banerjee M, et al. Mechanism of enhancement of eccrine sweating by localized heating. $J$ Appl Physiol. 1968;25(3):255-260. 